\title{
Ag/AgCl Film Electrodes Coated with Agarose Gel as Planar Reference Electrodes for Potentiometric Sensors
}

\author{
Tung Son Vinh Nguyen, Tien Minh Huynh, Thien Dien To, Tin Chanh Duc Doan ${ }^{*}$, Chien Mau Dang \\ Institute for Nanotechnology (INT), Vietnam National University - Ho Chi Minh City (VNUHCM), Vietnam
}

Copyright $\bigcirc 2018$ by authors, all rights reserved. Authors agree that this article remains permanently open access under the terms of the Creative Commons Attribution License 4.0 International License

\begin{abstract}
Silver/silver chloride $(\mathrm{Ag} / \mathrm{AgCl})$ is commonly used as a reference electrode in electrochemical measurements. However, commercial macroscopic $\mathrm{Ag} / \mathrm{AgCl}$ electrodes cannot be used in micro-electrochemical sensors. Thus, many scientists are trying to miniaturize reference electrodes to integrate into one sensor chip. In this paper a new approach for fabrication of $\mathrm{Ag} / \mathrm{AgCl}$ thin films coated with agarose gel as planar reference electrodes for potentiometric sensors is introduced. A silver thin film of 220-250 nm was sputtered and patterned on silicon dioxide/silicon substrates by lithography and lift-off techniques. $\mathrm{A} \mathrm{AgCl}$ layer was coated on the Ag film by using a $\mathrm{Ag}\left[\mathrm{NH}_{3}\right]_{2} \mathrm{Cl}$ complex at $80^{\circ} \mathrm{C}$ in vacuum. The thickness of the $\mathrm{AgCl}$ layers was about $5 \mu \mathrm{m}$. The $\mathrm{Ag} / \mathrm{AgCl}$ layers were then coated with an agarose gel. The $\mathrm{AgCl}$ layers were characterized by $\mathrm{X}$-ray diffraction, micro Raman spectroscopy and scanning electron microscopy. The Open Circuit Potential (OCP) measurements with the fabricated electrodes as reference electrodes in $\mathrm{pH} 7$ buffer solutions were performed in comparison with a commercial $\mathrm{Ag} / \mathrm{AgCl}$ electrode. The potential difference between the fabricated $\mathrm{Ag} / \mathrm{AgCl}$ electrodes and the commercial $\mathrm{Ag} / \mathrm{AgCl}$ electrode was insignificant. The coating of the agarose layer as a protection layer of the $\mathrm{Ag} / \mathrm{AgCl}$ electrodes enhanced the durability of the modified electrodes. The results indicated that the fabricated $\mathrm{Ag} / \mathrm{AgCl}$ thin films coated with the agarose gel could be used as planar reference electrodes for potentiometric sensors.
\end{abstract}

Keywords $\mathrm{Ag} / \mathrm{AgCl}, \quad$ Reference Electrode, $\mathrm{Ag}\left(\mathrm{NH}_{3}\right)_{2} \mathrm{Cl}$ Complex, Agarose

\section{Introduction}

Silver/silver chloride $(\mathrm{Ag} / \mathrm{AgCl})$ is often used as material of a reference electrode, which is used popularly in electrochemical measurements. However, conventional $\mathrm{Ag} / \mathrm{AgCl}$ electrodes are normally in macro-scale which cannot be employed in micro-electrochemical sensors [1]. Thus, many scientists are trying to minimize and integrate the reference electrode with the other sensors on a chip for biomedical and environmental applications [1-6].

A conventional $\mathrm{Ag} / \mathrm{AgCl}$ electrode is constructed by a silver wire coated with $\mathrm{AgCl}$. This $\mathrm{Ag} / \mathrm{AgCl}$ wire is then embedded into a liquid electrolyte of saturated $\mathrm{KCl}$. To fabricate a $\mathrm{Ag} / \mathrm{AgCl}$ micro-electrode, the electrode should be re-designed to a solid state instead. There are some methods to fabricate a solid state $\mathrm{Ag} / \mathrm{AgCl}$ electrode such as thin film deposition, electrochemical coating, screen printing, For example, Suzuki et al. fabricated a $\mathrm{Ag} / \mathrm{AgCl}$ thin film electrode by sputtering $300 \mathrm{~nm}$ silver layer and a $\mathrm{AgCl}$ layer was grown from the silver pattern by chronopotentiometric method at a constant current of 20 $\mu \mathrm{A}$ [7] or Kim et al. deposited 1,000 $\mathrm{nm}$ silver layer on a glass substrate using radio frequency sputtering and direct-current sputtering technique and chlorinated the $\mathrm{Ag}$ layer with a drop of $\mathrm{FeCl}_{3} 50 \mathrm{mM}$ [8]. Likewise Huang et al. sputtered an $\mathrm{Ag}$ layer with $4 \mu \mathrm{m}$ thickness on a $\mathrm{Si} / \mathrm{SiO}_{2}$ wafer and then chlorinated by electrochemical method in $0.1 \mathrm{M} \mathrm{HCl}$ at a constant voltage of $1.0 \mathrm{~V}$ [9]. Electrochemical method was also applied with other chlorine solution such as $\mathrm{KCl}, \mathrm{NaCl}, \ldots$ at different currents and potentials to grow the silver chloride layer on the silver backbone $[4,6,10,11]$. However, the electrochemical deposition might apply well only for an electrode with a thickness of a few micrometers because the chlorination causes the silver layer corroded rapidly. Deposition of a thick layer is not an advantage of the sputtering technique which is often used in nano-scaled thin films. Some studies prefer screen printing method. They could fabricate a quasi-reference electrode $\mathrm{Ag} / \mathrm{AgCl}$ without protecting layer or all-solid-state reference electrode $\mathrm{Ag} / \mathrm{AgCl} /$ electrolyte/protecting layer simply by printing the components of electrode step by step. For instance, Zielińska et al. [12] printed an ion-selective chloride electrode on a polyester foil content of silver contact, carbon layer and insulating layer. After each printing step, the layer of ink was cured at different conditions like heating or UV irradiation. Liao et al. also printed a solid 
state planar $\mathrm{Ag} / \mathrm{AgCl}$ electrode by screen printing with a silver paste, but the $\mathrm{AgCl}$ layer was formed by immersing the silver electrode in a $\mathrm{FeCl}_{3}$ solution $1 \mathrm{M}$ for 1 minute then the $\mathrm{KCl}$ agarose gel electrolyte was smeared on the $\mathrm{Ag} / \mathrm{AgCl}$ sequentially [13]. Idegami et al. [14] and Cranny et al. [15] used a paste of $\mathrm{Ag} / \mathrm{AgCl}$ mixture as a printing ink and used other kinds of paste and gel for printing the solid electrolyte and protection layer. The screen printing technique is an easy way to make a micro-scaled $\mathrm{Ag} / \mathrm{AgCl}$ electrode. However, the printed layers usually have the thickness ranging from several hundreds micrometers to some millimeters. In addition, with this technique, many components are required for the paste formula, which results in less purity of the printed electrode.

Bare $\mathrm{Ag} / \mathrm{AgCl}$ electrodes are easily degraded in solutions during electrochemical measurements. Therefore, protection layers are often coated on top of the $\mathrm{Ag} / \mathrm{AgCl}$ electrodes to increase durability. In some studies, the surface of $\mathrm{Ag} / \mathrm{AgCl}$ electrodes was covered with a polymeric electrolyte $[16,17]$. Besides, Nafion $[18,19]$ or a metallic layer [20] could be used to protect the $\mathrm{Ag} / \mathrm{AgCl}$ thin film in planar reference electrodes. Agarose gel has been used as an electrolyte layer in combination with chloroprene rubber to form a protection layer of the $\mathrm{Ag} / \mathrm{AgCl}$ electrodes [13, 21].

In this study, a new approach was used to fabricate $\mathrm{Ag} / \mathrm{AgCl}$ thin films for planar reference electrodes. $\mathrm{A} \mathrm{AgCl}$ thin layer was deposited on the sputtered Ag layer surface by drop coating. A complex of $\mathrm{Ag}\left(\mathrm{NH}_{3}\right)_{2} \mathrm{Cl}$ was used to deposit the $\mathrm{AgCl}$ layer. Thanks to high solubility of this complex in water, the solution could be drop-coated easily. Furthermore, the complex had reversibility so it could be returned to the salt form $-\mathrm{AgCl}$ by slightly heating. The reactions of composition and decomposition of the $\mathrm{Ag}\left(\mathrm{NH}_{3}\right)_{2} \mathrm{Cl}$ complex are shown as Eq. 1 and Eq. 2 below.

$\mathrm{AgCl}(\mathrm{s})+2 \mathrm{NH}_{4} \mathrm{OH}(\mathrm{aq}) \leftrightarrows \mathrm{Ag}\left(\mathrm{NH}_{3}\right)_{2} \mathrm{Cl}(\mathrm{aq})+2 \mathrm{H}_{2} \mathrm{O}$

$$
\mathrm{Ag}\left(\mathrm{NH}_{3}\right)_{2} \mathrm{Cl}(\mathrm{aq}) \rightarrow \mathrm{AgCl}(\mathrm{s})+2 \mathrm{NH}_{3}(\mathrm{~g})
$$

The $\mathrm{AgCl}$ layer reformed from the decomposition of the $\mathrm{Ag}\left(\mathrm{NH}_{3}\right)_{2} \mathrm{Cl}$ complex easily covered the surface of the $\mathrm{Ag}$ electrode. Moreover, less contamination was caused because the decomposition produced the vapor gas as in Eq. 2. Finally, the $\mathrm{Ag} / \mathrm{AgCl}$ electrode layer was covered by a layer of agarose gel.

\section{Materials and Methods}

\subsection{Materials}

Acetone, iso-propanol and ethanol were purchased from Merck, Germany. Ma-P1215 positive photoresist, hexamethyldisilazane (HMDS) and ma-MF_320 developer solution were purchased from Micro Resist, Germany.

Silver nitrate $\left(\mathrm{AgNO}_{3}\right)$ 99\% was purchased from Scharlab S.L., Spain. Sulfuric acid $\left(\mathrm{H}_{2} \mathrm{SO}_{4}\right)$ 98\%, hydrogen peroxide $\left(\mathrm{H}_{2} \mathrm{O}_{2}\right) 30 \%$, sodium chloride $(\mathrm{NaCl})$, ammoniac solution $\left(\mathrm{NH}_{3}\right) 25 \%$ and potassium chloride $(\mathrm{KCl})$ were purchased from Xilong, China. Agarose powder $100 \%$ was purchased from Vietxo Co., Vietnam. Deionized (DI) water was supplied by a DI system (Purelab Ultra, Elga Co., UK), the resistance of the outlet water was 18.2 MOhms. The $\mathrm{pH}$ buffer solutions from Hanna Instruments Vietnam were used as electrolyte in the electrochemical measurements.

\subsection{Fabrication of the Ag Planar Electrodes}

The Ag electrodes were fabricated with dimension as shown in Fig. 1. The Ag electrodes were fabricated on the (100) silicon wafers (Okmetic, Finland) with 4 inch diameter, $380 \mu \mathrm{m}$ thickness, the surface resistance of approximately 5-10 $\Omega . \mathrm{cm}$. The wafers were washed with piranha solution (mixture of $15 \mathrm{ml} \mathrm{H}_{2} \mathrm{SO}_{4} 98 \%$ and $5 \mathrm{ml}$ $\mathrm{H}_{2} \mathrm{O}_{2} 30 \%$ ), DI water, acetone and iso-propanol. After cleaning, a $\mathrm{SiO}_{2}$ insulator layer with $700 \mathrm{~nm}$ thickness was coated on the silicon wafer by the oxidation furnace PEO 601 (ATV, Germany). After that, the $\mathrm{Si} / \mathrm{SiO}_{2}$ wafer was washed with piranha solution, DI water, acetone and iso-propanol respectively for 5 minutes.

The photolithography process was used for fabrication of the Ag planar electrodes. The $\mathrm{Ti}$ and Ag layers were sputtered by the sputtering system Univex 350 (Leybold, Germany). The Ti layer with a few nanometers was used as an adhesive layer between the wafer $\mathrm{Si} / \mathrm{SiO}_{2}$ and the $\mathrm{Ag}$ layer on the top.

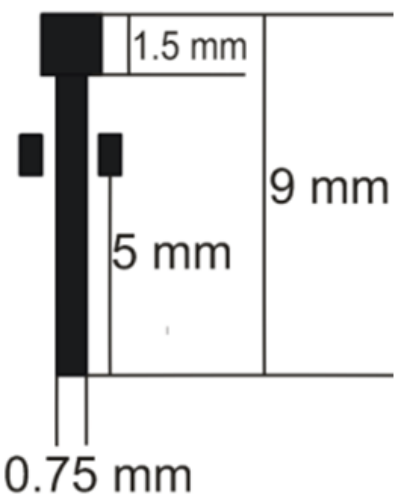

Figure 1. Dimension of a silver electrode

\subsection{Coating AgCl on the Ag Electrode}

$1 \mathrm{ml} \mathrm{AgNO}_{3} 0.2 \mathrm{M}$ solution was mixed with $1 \mathrm{ml} \mathrm{NaCl}$ $0.3 \mathrm{M}$ solution to produce precipitated $\mathrm{AgCl}$. This salt was rinsed at least 5 times, each time with $10 \mathrm{ml}$ of DI water to eliminate the residual reactants. After rinsing step, $170 \mu \mathrm{l}$ $\mathrm{NH}_{3} 25 \%$ solution was added to dissolve $\mathrm{AgCl}$ and subsequently form a soluble $\mathrm{Ag}\left(\mathrm{NH}_{3}\right)_{2} \mathrm{Cl}$ complex. Finally, the $\mathrm{Ag}\left(\mathrm{NH}_{3}\right)_{2} \mathrm{Cl}$ complex was distilled in DI water with total volume of $1.7 \mathrm{ml}$ to produce $0.021 \mathrm{~g} / \mathrm{ml}$ concentration of the complex.

$4 \mu \mathrm{l}$ of the distilled complex solution was dropped on the fabricated Ag electrode. Then the Ag electrode with 
the complex drop was heated at $80^{\circ} \mathrm{C}$ for 5 minutes in a vacuum oven. Dropping manipulation was repeated once more on the same position and then heated at $80^{\circ} \mathrm{C}$ in vacuum for 30 minutes. Fig. 2 shows the $\mathrm{Ag} / \mathrm{AgCl}$ electrode before and after $\mathrm{AgCl}$ coating).
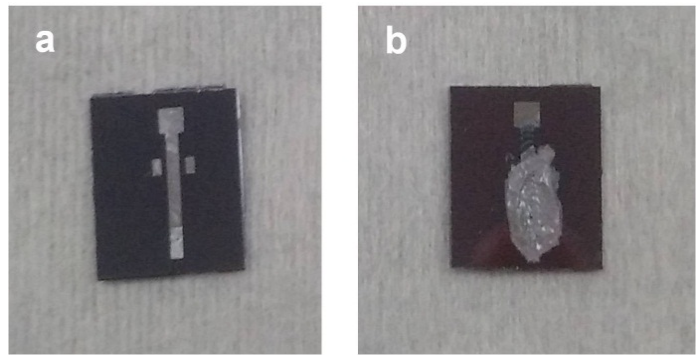

Figure 2. The photos of the $\mathrm{Ag}$ electrode before (a) and after (b) coated with the $\mathrm{AgCl}$ layer.

\subsection{Coating Agarose Layer on the $\mathrm{Ag} / \mathrm{AgCl}$ Electrode}

The agarose solution $2 \%$ was prepared by diluting $0.2 \mathrm{~g}$ agarose powder in $10 \mathrm{ml}$ DI water at $80^{\circ} \mathrm{C}$. The solution was stirred for 10 - 15 minutes until agarose powder was completely dissolved in the solution. $5 \mu 1$ of the agarose solution was dropped on the surface of the $\mathrm{Ag} / \mathrm{AgCl}$ electrode and left at room temperature for 24 hours to stabilize. Fig. 3 shows the $\mathrm{Ag} / \mathrm{AgCl} /$ agarose electrode before and after drying.
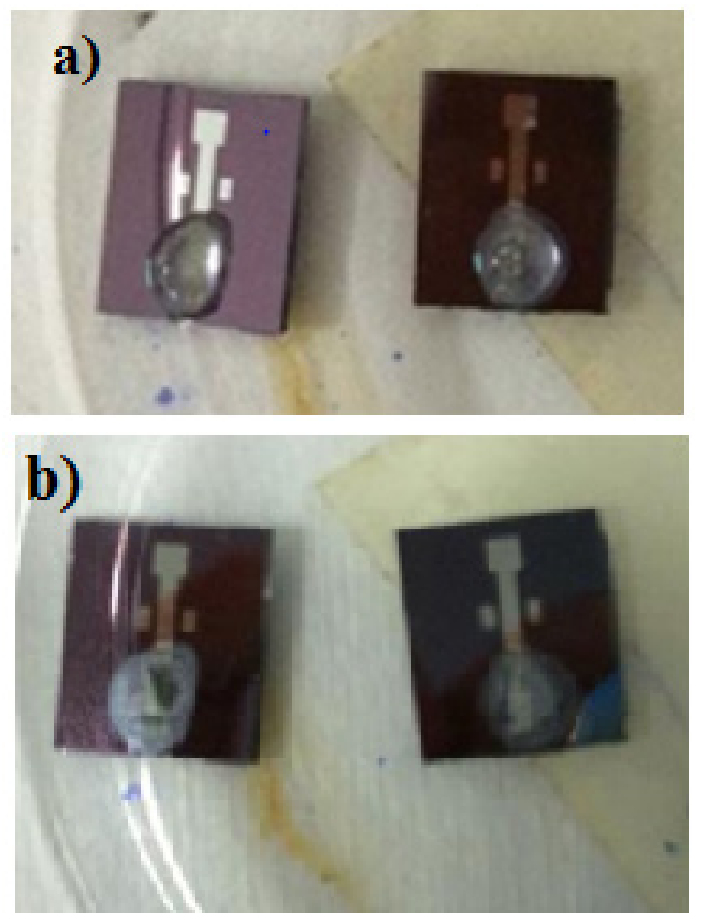

Figure 3. The photos of the $\mathrm{Ag}|\mathrm{AgCl}|$ Agarose electrodes before (a) and after (b) drying.

\subsection{Characterization}

Thickness of the $\mathrm{Ag} / \mathrm{AgCl}$ electrodes was measured by a stylus profiler Dektak 6M (Veeco, USA) and Scanning Electron Microscopy - SEM (JSM-6480LV, Jeol, Japan). Structural characterization of $\mathrm{Ag} / \mathrm{AgCl}$ was performed by X-Ray diffraction (XRD) on Diffraktometer D500 (Siemens, Germany), Energy dispersive X-ray spectroscopy (EDS) integrated in the FE-SEM S4800 (Hitachi, Japan), Micro Raman spectroscopy on Lab RAM 300 (Jobin Yvon, France).

Thickness of the $\mathrm{Ag} / \mathrm{AgCl} /$ agarose layer was measured by the stylus profiler Dektak 6M (Veeco, USA). Physical stability and durability of the $\mathrm{Ag} / \mathrm{AgCl} /$ agarose layer was tested by immersing the fabricated electrodes in DI water and $\mathrm{pH} 7$ buffer solution for various periods (from 2- 24 hours).

\subsection{Electrochemical Characterization}

The fabricated $\mathrm{Ag} / \mathrm{AgCl}$ electrodes and the $\mathrm{Ag} / \mathrm{AgCl} /$ agarose electrodes were used to measure the Open Circuit Potential (OCP) vs. the commercial $\mathrm{Ag} / \mathrm{AgCl}$ reference electrode (Basi Inc., US) and the potential of the electrodes in the $\mathrm{pH} 7$ buffer solution was measured with the Autolab PGSTAT-302N, Metrohm, the Netherlands. The measurement time was 300 seconds and the $\mathrm{dE} / \mathrm{dt}$ limit was $10^{-6}$. The measurement would be stopped when the change of the potential over time reached $10^{-6}$. During the measurement time, there was no current through the electrochemical cell.

For the $\mathrm{Ag} / \mathrm{AgCl}$ electrodes, the OCP measurement was performed for 3 times. The $\mathrm{Ag} / \mathrm{AgCl} /$ agarose electrode's OCP measurement was performed for 8 times in 2 weeks.

\section{Results and Discussion}

\subsection{Characterization of the Fabricated Ag/Agcl Electrodes}

The thickness of the $\mathrm{Ag}$ and $\mathrm{AgCl}$ layers was measured by Dektak 6M. The thickness of the Ag layer was $187 \pm$ $20 \mathrm{~nm}$, and the thickness of the $\mathrm{Ag} / \mathrm{AgCl}$ layer was 4,689 $\pm 278 \mathrm{~nm}$. The result was in good accordance with the observation of the SEM images on the cross section of the $\mathrm{Ag} / \mathrm{AgCl}$ layer (Fig. 4). The SEM image showed that the $\mathrm{Ag} / \mathrm{AgCl}$ layer was formed quite uniformly and the thickness was about $5 \mu \mathrm{m}$. 


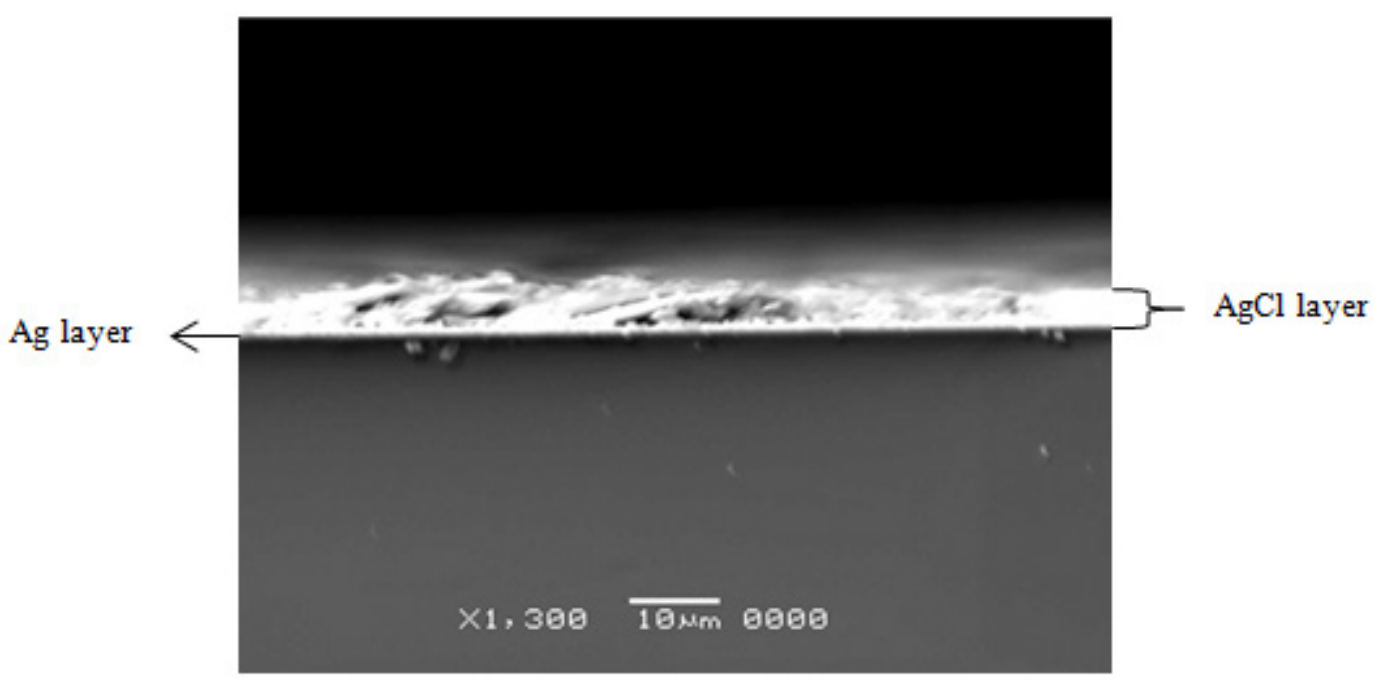

Figure 4. The SEM image on the cross section of the $\mathrm{Ag} / \mathrm{AgCl}$ layer.

The formation of $\mathrm{AgCl}$ was determined by XRD which exhibited the specific diffraction peaks of $\mathrm{AgCl}$ (Fig. 5). Unlike the other reports, the XRD of $\mathrm{AgCl}$ formed by decomposition of $\mathrm{Ag}\left(\mathrm{NH}_{3}\right)_{2} \mathrm{Cl}$ had a highest peak at $2 \mathrm{O}=$ $28^{\circ}$ (111) instead of $32^{\circ}$ (200). This revealed that the $\mathrm{AgCl}$ crystal might not exist in nanosphere as in synthesis of $\mathrm{Hu}$ et al. [22] or nanocubic structure of Yang et al. [23] or the others of nanoparticle [24] but with another morphology. The crystallization of the $\mathrm{AgCl}$ mainly followed by the development of planar (111) implied that the $\mathrm{AgCl}$ crystal might be grown from the vertices of an original cubic to construct a branch type of crystal as described by Lou [25] and Tian [26]. Because the $\mathrm{AgCl}$ crystallized from the $\mathrm{Ag}\left(\mathrm{NH}_{3}\right)_{2} \mathrm{Cl}$ complex without inhibition of any solvent or surfactant, crystallization had enough time to rebuild the lattice gradually and was not suspended. As a result, crystallization constructed a micro-branched crystal with the low surface energy of $-0.273 \mathrm{Jm}^{-3}$ of the $\mathrm{AgCl}$ (111) facets [25].

On the other hand, the Ag peak did not appear in the XRD spectrum, it could be due to the huge difference in thickness between $\mathrm{Ag}$ layer and $\mathrm{AgCl}$ layer. The thickness of $\mathrm{AgCl}$ layer was 40 times thicker than the thickness of the Ag layer, so the peak of Ag layer could not appear in the XRD spectrum.

The EDS analysis (Fig. 6) indicated the peaks of the elements present in the sample, which are in good agreement with the reported EDS results [16]. In the EDS results, there were mainly $\mathrm{Ag}$ and $\mathrm{Cl}$ in the sample, the molar ratio of $\mathrm{Ag}: \mathrm{AgCl}$ was 1:1.3. The residual contaminants from the complex such as $\mathrm{N}, \mathrm{H}$ were not present. Nevertheless, there was a small content of $\mathrm{Si}$ and $\mathrm{O}$ which were from the $\mathrm{SiO}_{2}$ substrate. The EDS results showed that the $\mathrm{AgCl}$ was produced with high purity.

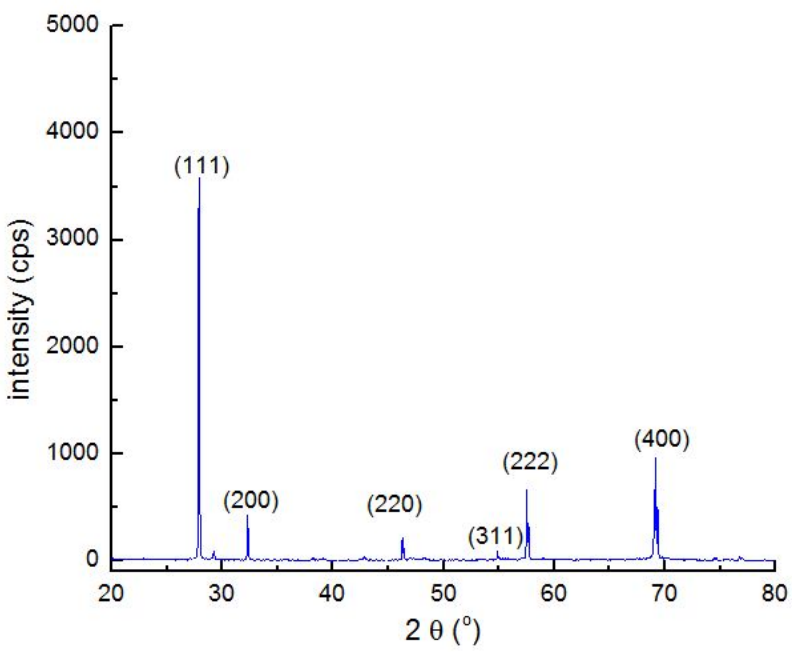

Figure 5. The $\mathrm{XRD}$ of the $\mathrm{AgCl}$ layer formed on the Ag layer.

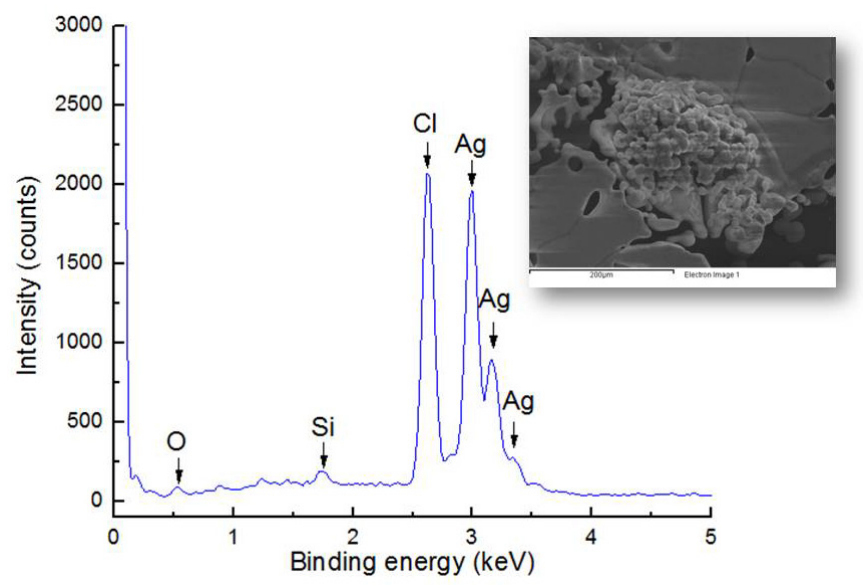

Figure 6. The EDS spectrum of the $\mathrm{Ag}$ electrode coated with the $\mathrm{AgCl}$ layer. 
To consolidate the above results, the Raman spectrum of the $\mathrm{Ag} / \mathrm{AgCl}$ electrode was performed (Fig 6). There was a good accordance in Raman shift with other reported results [27]. For instance, the vibration of the Ag lattice and the stretching of Ag-Cl bond could be found at the Raman shift of $99,135,225 \mathrm{~cm}^{-1}$ corresponding to $95,143,233 \mathrm{~cm}^{-1}$ of the ref. [27]. It could be concluded that the $\mathrm{AgCl}$ layer was formed on the Ag layer.

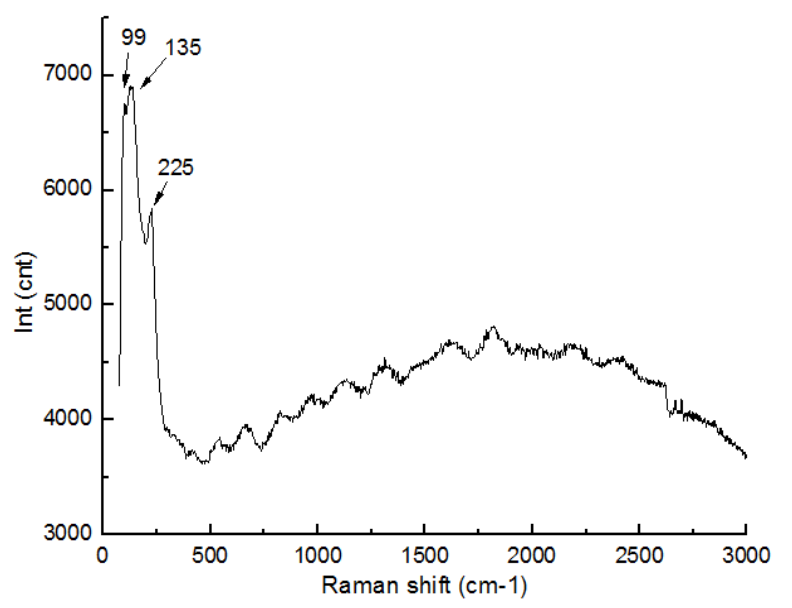

Figure 7. The Raman spectrum of the $\mathrm{Ag} / \mathrm{AgCl}$ layer.

\subsection{Characterization of the Fabricated Ag/Agcl/Agarose Electrode}

The thickness of the $\mathrm{Ag} / \mathrm{AgCl} /$ agarose electrodes measured by Dektak $6 \mathrm{M}$ was $28.6 \mu \mathrm{m} \pm 3.5 \mu \mathrm{m}$. The thickness of the agarose layer could be varied by adjusting to the concentration of the agarose solution.

On the other hand, the physical stability of the modified electrodes was good. After immersed in DI water and $\mathrm{pH} 7$ solution for 2 hours, the fabricated electrodes remained stable. The surface of the electrodes was not damaged and the $\mathrm{Ag} / \mathrm{AgCl} /$ agarose layer was still on the electrodes. Fig. 8 shows the electrodes before and after immersed in DI water, $\mathrm{pH} 7$ solution for 2 hours.

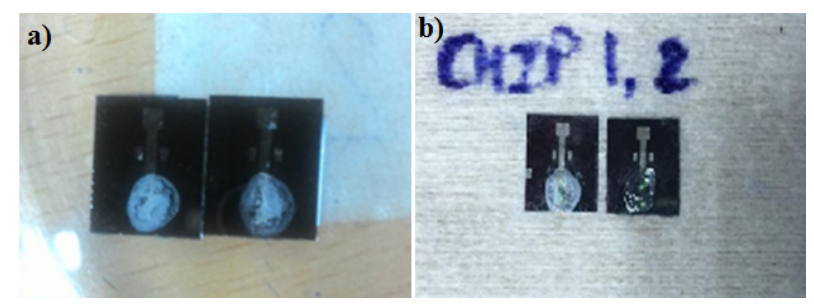

Figure 8. The photos of the $\mathrm{Ag} / \mathrm{AgCl} /$ agarose electrodes before (left) and after (right) immersed into DI water and $\mathrm{pH} 7$ solution for 2 hours.

The right hand side electrode (Fig. $8 \mathrm{~b}$ ) was just taken out of the solution after 2 hours of immersing, then the electrode was left at room temperature for 10-15 minutes to dry out. After drying, the electrode came back as the left hand side electrode of Fig. 8b. It was clearly shown that the modified electrode remained unchanged after 2 hours of immersing in DI water and $\mathrm{pH} 7$ solution.

\subsection{Electrochemical Characterization}

Electrochemical characterization of the fabricated $\mathrm{Ag} / \mathrm{AgCl}$ electrodes was performed by comparison of the potential difference between the fabricated $\mathrm{Ag} / \mathrm{AgCl}$ electrodes with the commercial $\mathrm{Ag} / \mathrm{AgCl}$ reference electrode. Both the $\mathrm{Ag} / \mathrm{AgCl}$ electrodes were immersed in a pH 7 buffer and the OCP measurement was performed by the Autolab PGSTAT 302N, Metrohm, the Netherlands. The OCP mean value of the $\mathrm{Ag} / \mathrm{AgCl}$ electrodes after 5 repeated measurements was $20.3 \pm 2.7 \mathrm{mV}$. The potential difference is lower and more stable in comparison with the reported potential variations $(187 \mathrm{mV}$ in $[9,28]$ and $27 \pm 3$ $\mathrm{mV}$ in $[9,28])$. The difference in dimension of the electrodes is attributed to the difference in the OCP values between the fabricated $\mathrm{Ag} / \mathrm{AgCl}$ electrode and the commercial $\mathrm{Ag} / \mathrm{AgCl}$ reference electrode. The measurements had good repeatability with acceptable errors. However, it was observed that after the OCP measurements, the $\mathrm{Ag} / \mathrm{AgCl}$ electrode layer on the chip was slightly damaged (as shown in Fig. 9) and the $\mathrm{Ag} / \mathrm{AgCl}$ layer was fully degraded after 4 times of OCP measurements.
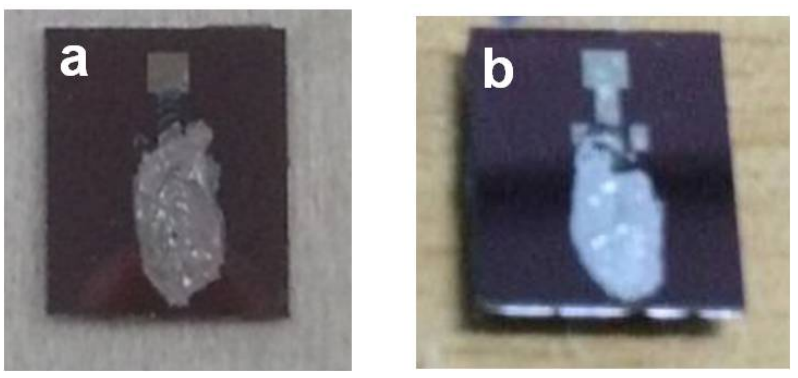

Figure 9. The photos of the $\mathrm{Ag} / \mathrm{AgCl}$ electrode before (a) and after OCP measurements (b).

The electrochemical properties of the $\mathrm{Ag} / \mathrm{AgCl} /$ agarose electrodes were determined by using the same experimental set up as with the $\mathrm{Ag} / \mathrm{AgCl}$ electrodes. In the first week of measurements, the OCP mean value of the $\mathrm{Ag} / \mathrm{AgCl} /$ agarose electrodes (after 5 repeated times) was $252 \mathrm{mV}$ and the deviation values of five (5) times of measurement was $\pm 14 \mathrm{mV}$. One week later, the $\mathrm{Ag} / \mathrm{AgCl} /$ agarose electrodes were measured again. The OCP mean value of the modified electrodes after 3 repeated times was $187 \pm 17 \mathrm{mV}$. The large change of the OCP values (approximately 9 to 10 times) of the $\mathrm{Ag} / \mathrm{AgCl} /$ agarose electrodes was attributed to the change of the structure of the modified electrodes. However, it was found that the addition of the agarose layer on the $\mathrm{Ag} / \mathrm{AgCl}$ electrodes helped to enhance durability of the $\mathrm{Ag} / \mathrm{AgCl}$ electrodes (8 times of measurements).

The potential difference between the fabricated $\mathrm{Ag} / \mathrm{AgCl}, \mathrm{Ag} / \mathrm{AgCl} /$ agarose electrodes and the commercial $\mathrm{Ag} / \mathrm{AgCl}$ electrode was the result of directly contact between the fabricated $\mathrm{Ag} / \mathrm{AgCl}, \mathrm{Ag} / \mathrm{AgCl} /$ agarose 
electrode and the electrolyte solution without a protection layer. Without the protection layer which was filled with high concentration of $\mathrm{Cl}^{-}$, the electrode-electrolyte contact of the fabricated $\mathrm{Ag} / \mathrm{AgCl}$ electrode caused the activity of $\mathrm{Cl}^{-}$unstable. This instability could also make the difference in OCP value of the fabricated $\mathrm{Ag} / \mathrm{AgCl}$ electrode and the commercial $\mathrm{Ag} / \mathrm{AgCl}$ electrode. This potential variation could be reduced by coating a protection layer which was full-filled with $\mathrm{Cl}^{-}$on the $\mathrm{Ag} / \mathrm{AgCl}$ electrode layer as suggested in the ref. $[4,9]$.

\subsection{Optimal Condition Demand}

$\mathrm{The} \mathrm{Ag} / \mathrm{AgCl}$ reference electrodes with specific design were fabricated by photo-lithography, physical and chemical deposition in a very simple process. The potential difference between the fabricated electrode and the commercial $\mathrm{Ag} / \mathrm{AgCl}$ electrode was $20.3 \pm 2.7 \mathrm{mV}$, which is lower and more stable than others publish reports [9, 28]. The agarose layer acted as a protection layer in order to enhance the durability of the fabricated electrode. The potential difference increase could be due to the increase in thickness of the electrodes. The durability of the fabricated electrode could be improved by storing the electrode in the solution which has high concentration of $\mathrm{Cl}^{-}$. The potential variation can be reduced by decreasing the thickness of the electrode (decrease the thickness of the $\mathrm{AgCl}$ layer or the agarose layer).

\section{Conclusions}

$\mathrm{The} \mathrm{Ag} / \mathrm{AgCl}$ reference electrodes with a thickness of 5 $\mu \mathrm{m}$ and high purity were fabricated by lithography, sputtering deposition technique and chemical deposition from reversibility of the $\mathrm{Ag}\left(\mathrm{NH}_{3}\right)_{2} \mathrm{Cl}$ complex in a simple process. The fabricated $\mathrm{Ag} / \mathrm{AgCl}$ electrodes and the $\mathrm{Ag} / \mathrm{AgCl} /$ agarose electrodes were still stable after undergoing the electrochemical measurements. The potential difference of the fabricated electrodes was lower and more stable in comparison with the reported potential variations with an acceptable error. Addition of the agarose layer as the protection layer of the $\mathrm{Ag} / \mathrm{AgCl}$ electrodes enhanced the durability of the modified electrodes. The potential variation could be reduced by coating a protection layer which was filled with a high concentration of $\mathrm{Cl}^{-}$. The results show that the fabricated $\mathrm{Ag} / \mathrm{AgCl}$ electrode could be used as a planar reference electrode in potentiometric sensors for aquacultural farming.

\section{Acknowledgements}

The authors highly appreciate the financial support of Vietnam National University - Ho Chi Minh City for this research under the grant number B2014-32-01.

\section{REFERENCES}

[1] $\mathrm{Hu}, \mathrm{J}$. , et al., All-Solid-State Reference Electrodes Based on Colloid-Imprinted Mesoporous Carbon and Their Application in Disposable Paper-based Potentiometric Sensing Devices. Analytical Chemistry, 2015. 87(5): p. 2981-2987.

[2] Lee, J.-H., et al., Needle-type multi-analyte MEMS sensor arrays for in situ measurements in biofilms, in Emerging Environmental Technologies, V. Shah, Editor. 2010, Springer: Dordrecht. p. 115-145.

[3] Lee, J.-H., et al., MEMS Needle-type Sensor Array for in Situ Measurements of Dissolved Oxygen and Redox Potential. Environmental Science \& Technology, 2007. 41(22): p. 7857-7863.

[4] Mamińska, R., A. Dybko, and W. Wróblewski, All-solid-state miniaturised planar reference electrodes based on ionic liquids. Sensors and Actuators B: Chemical, 2006. 115(1): p. 552-557.

[5] Guth, U., et al., Solid-state reference electrodes for potentiometric sensors. Journal of Solid State Electrochemistry, 2008. 13(1): p. 27-39.

[6] Dybko, A., et al., Miniaturized back-side contact transducer for potentiometric sensors. Analytica Chimica Acta, 2003. 485(1): p. 103-109.

[7] Suzuki, H., et al., Problems associated with the thin-film $\mathrm{Ag} / \mathrm{AgCl}$ reference electrode and a novel structure with improved durability. Sensors and Actuators B: Chemical, 1998. 46(2): p. 104-113.

[8] Kim, T., S. Hong, and S. Yang, A Solid-State Thin-Film $\mathrm{Ag} / \mathrm{AgCl}$ Reference Electrode Coated with Graphene Oxide and Its Use in a pH Sensor. Sensors, 2015. 15(3): p. 6469-6482.

[9] Huang, I.Y., R.-S. Huang, and L.-H. Lo, Improvement of integrated $\mathrm{Ag} / \mathrm{AgCl}$ thin-film electrodes by $\mathrm{KCl}$-gel coating for ISFET applications. Sensors and Actuators B: Chemical, 2003. 94(1): p. 53-64.

[10] Brewer, P.J., R.J. Leese, and R.J.C. Brown, An improved approach for fabricating $\mathrm{Ag} / \mathrm{AgCl}$ reference electrodes. Electrochimica Acta, 2012. 71: p. 252-257.

[11] Valdés-Ramírez, G., et al., Design and Construction of Solid State $\mathrm{Ag} / \mathrm{AgCl}$ Reference Electrodes Through Electrochemical Deposition of $\mathrm{Ag}$ and $\mathrm{AgCl}$ Onto a Graphite/Epoxy Resin-Based Composite. Parte 1: Electrochemical Deposition of Ag Onto a Graphite/Epoxy Resin-Based Composite. Int. J. Electrochem. Sci., 2011. 6(4): p. 971-987.

[12] Zielińska, R., et al., All-solid-state planar miniature ion-selective chloride electrode. Analytica Chimica Acta, 2002. 451(2): p. 243-249.

[13] Liao, W.-Y. and T.-C. Chou, Fabrication of a Planar-Form Screen-Printed Solid Electrolyte Modified $\mathrm{Ag} / \mathrm{AgCl}$ Reference Electrode for Application in a Potentiometric Biosensor. Analytical Chemistry, 2006. 78(12): p. 4219-4223. 
[14] Idegami, K., et al., Fabrication and Characterization of Planar Screen-Printed $\mathrm{Ag} / \mathrm{AgCl}$ Reference Electrode for Disposable Sensor Strip. Japanese Journal of Applied Physics, 2010. 49(9): p. 097003.

[15] Cranny, A., et al., Screen-printed potentiometric $\mathrm{Ag} / \mathrm{AgCl}$ chloride sensors: Lifetime performance and their use in soil salt measurements. Sensors and Actuators A: Physical, 2011. 169(2): p. 288-294.

[16] Diamond, D., et al., Evaluation of a new solid-state reference electrode junction material for ion-selective electrodes. Electroanalysis, 1994. 6(11-12): p. 962-971.

[17] Shinwari, M.W., et al., Microfabricated Reference Electrodes and their Biosensing Applications. Sensors (Basel, Switzerland), 2010. 10(3): p. 1679-1715.

[18] Kim, T.Y., S.A. Hong, and S. Yang, A Solid-State Thin-Film $\mathrm{Ag} / \mathrm{AgCl}$ Reference Electrode Coated with Graphene Oxide and Its Use in a pH Sensor. Sensors (Basel, Switzerland), 2015. 15(3): p. 6469-6482.

[19] Nolan, M.A., S.H. Tan, and S.P. Kounaves, Fabrication and Characterization of a Solid State Reference Electrode for Electroanalysis of Natural Waters with Ultramicroelectrodes. Analytical Chemistry, 1997. 69(6): p. 1244-1247.

[20] Kim, H.R., et al., Enhancement of physical and chemical properties of thin film $\mathrm{Ag} / \mathrm{AgCl}$ reference electrode using a Ni buffer laver. Sensors and Actuators B: Chemical, 2004. 97(2-3): p. $348-354$

[21] Simonis, A.L., H.; Wang, J.; Schöning, J., Strategies of Miniaturised Reference Electrodes Integrated in a Silicon Based "one chip" pH Sensor. Sensors, 2003. 3(9): p. 9.
[22] $\mathrm{Hu}, \mathrm{P}$. , et al., Engineering the metathesis and oxidation-reduction reaction in solid state at room temperature for nanosynthesis. Scientific Reports, 2014. 4.

[23] Yang, Y., et al., Preparation of $\mathrm{AgCl}$ Nanocubes and Their Application as Efficient Photoinitiators in the Polymerization of $N$-Isopropylacrylamide. The Journal of Physical Chemistry B, 2015. 119(46): p. 14807-14813.

[24] Siddiqui, M.R.H., et al., Synthesis and Characterization of Silver Oxide and Silver Chloride Nanoparticles with High Thermal Stability. Asian Journal of Chemistry, 2013. 23(6): p. 3405-3409.

[25] Lou, Z., et al., A 3D $\mathrm{AgCl}$ Hierarchical Superstructure Synthesized by a Wet Chemical Oxidation Method. Chemistry - A European Journal, 2012. 18(50): p. 16090-16096.

[26] Tian, B. and J. Zhang, Morphology-Controlled Synthesis and Applications of Silver Halide Photocatalytic Materials. Catalysis Surveys from Asia, 2012. 16(4): p. 210-230.

[27] Martina, I., et al., Micro-Raman Characterisation of Silver Corrosion Products: Instrumental Set Up and Reference Database. E-Preservation Science, 2012.

[28] Prissanaroon-Ouajai, W., P. James Pigram, and A. Sirivat, Simple Solid-state $\mathrm{Ag} / \mathrm{AgCl}$ Reference Electrode and Its Integration with Conducting Polypyrrole Electrode for the Production of All-solid-state $p H$ Sensor. KMUTNB International Journal of Applied Science and Technology, 2016: p. 1-9. 